\title{
Aspectos psicogenéticos da prática do Jogo das Quatro Cores ${ }^{1}$
}

\author{
Lorena Carla Macedo da Silva \\ Antonio Carlos Ortega \\ Universidade Federal do Espírito Santo
}

\begin{abstract}
Resumo
Este trabalho teve por objetivo investigar, em uma perspectiva psicogenética, a influência do tipo de prática (individual ou em dupla) no nível de compreensão alcançado por crianças de 10 e 12 anos no Jogo das Quatro Cores. Na primeira etapa, avaliou-se o nível de compreensão das crianças quando pintavam três figuras, sendo que a maioria se encontrava no nível I. Na segunda etapa, realizou-se uma prática do jogo por meio de outras duas figuras, quando metade das crianças tentou pintá-las individualmente e, o restante, em dupla. Na terceira etapa, as crianças foram reavaliadas com base nos mesmos instrumentos utilizados anteriormente, sendo que a maioria dos mais jovens se encontrava no nível I e, a maioria dos mais velhos, no nível II. Comparando-se os resultados das duas avaliações, observou-se uma melhora no nível de compreensão, após a prática do jogo. No entanto, essa melhora não pôde ser atribuída ao tipo de prática realizada.
\end{abstract}

Palavras-chave: Psicogênese, Fazer e Compreender, Jogos de Regras, Jogos das Quatro Cores.

\begin{abstract}
Psychogenetical aspects from the practice of the Four Colors Game. This work aimed at investigating the influences from the practice type (individual or in couples) on the understanding level reached by children aged 10 and 12 years old in the Four Colors Game. In the first stage, the understanding level was assessed from the subjects when painting three illustrations, and most of them was in the level I. In the second stage, a practice of the game took place through other two illustrations, when half of the subjects tried to paint them individually and the other half in couples. In the third stage, the subjects were reassessed according to the same instruments used previously, and most of the youngest reached the level I while most of the oldest reached the level II. By comparing the results of the evaluations, we noticed an improvement in the understanding level, after the practice of the game. However, that improvement could not be attributed to the practice type of game.
\end{abstract}

Key words: Psychogenesis, Doing and Understanding, Rules Games, Four Colors Games.

$\mathrm{O}$ Jogo das Quatro Cores foi criado em 1852, por Francis Guthrie, que percebeu que a maioria dos mapas dos atlas era pintada com quatro cores, respeitando-se o critério de não pintar dois países vizinhos com a mesma cor. Pediu a seu irmão, Frederick, que, como ele, era um aluno da Universidade de Londres, que demonstrasse matematicamente o teorema de que quatro cores bastariam para colorir qualquer mapa sem que as regiões vizinhas tivessem a mesma cor $^{2}$.

De acordo com as regras do Jogo das Quatro Cores, em uma de suas primeiras modalidades, o jogador deve pintar uma figura que lhe será apresentada, subdividida em regiões, utilizando somente quatro cores, sem que regiões vizinhas sejam pintadas da mesma cor. Essa modalidade é conhecida como Colorindo Figuras Individualmente.

Outras modalidades desse jogo foram citadas por Macedo, Petty e Passos (1997).

Uma delas, denominada Cilada de Cores, deve ser jogada por duas pessoas, sendo uma contra a outra. Ambas devem jogar a mesma figura e utilizar os mesmos quatro lápis de cor. O objetivo é criar uma situação da qual o adversário não terá saída.

$\mathrm{Na}$ modalidade intitulada Inventando Figuras, dois jogadores devem criar uma figura a partir de um papel em branco, alternando-se na construção da forma e das subdivisões, que, a critério dos próprios jogadores, sejam suficientes. A seguir, 
começam a colorir as regiões, alternando-se, conforme a modalidade Cilada de Cores.

A modalidade conhecida por Stephen Barr também não requer uma figura previamente escolhida. É semelhante à modalidade Inventando Figuras: os jogadores constroem a figura a ser colorida, porém, simultaneamente, devem colorir as regiões já construídas.

Há também o Dominó das Quatro Cores, que consiste em uma base quadrada de madeira e 18 peças de cores e tamanhos diferentes, cujo objetivo é arranjá-las na base, de modo que peças da mesma cor não podem ser dispostas em contato umas com as outras, nem mesmo em seus cantos.

Vários estudos foram realizados no Brasil, principalmente na última década, utilizando o Jogo das Quatro Cores como instrumento de pesquisa. Entre eles, destacam-se aqueles realizados por Petty (1995), Santos (1998), Petty, Carracedo e Macedo (1999), e Ortega, Fiorot e Silva (2000), que serão brevemente descritos a seguir.

Petty (1995) faz uma análise do uso do Jogo das Quatro Cores a partir da observação dos erros e auto-correções realizadas pelas crianças ao jogá-lo. A autora optou por utilizar, nessa análise, a modalidade Dominó das Quatro Cores, por ser um instrumento de fácil manipulação e por produzir um efeito visual impactante para o jogador, facilitando à criança a percepção do erro cometido. Além disso, essa modalidade permite que a criança, durante a partida, possa auto-corrigir os erros cometidos, reorganizando as peças de um modo diferente. Desse modo, a distância entre cometer o erro e corrigi-lo é bastante diminuída com o desenrolar da partida.

Assim, de acordo com Petty (1995), o Dominó das Quatro Cores

(...) tem um papel importante para estimular a criança a observar seus erros, num contexto em que evitá-los (planejando, antecipando, coordenando etc) é condição para ganhar. (...) Assim, num processo gradativo e intenso, acaba descobrindo que é importante planejar (se não quer mais errar) e, porque planeja, antecipa erros e produz acertos (p. 98).

Com base na proposta Psicopedagógica Construtivista de Macedo (1992), segundo a qual jogos de regras servem como instrumentos de avaliação dos processos cognitivos e de intervenção psicopedagógica, Santos (1998) desenvolve um estudo psicogenético utilizando também a modalidade Dominó das Quatro Cores.

Nesse trabalho, a autora utilizou matrizes simplificadas desse jogo, que eram, a princípio, apresentadas às crianças, sendo que o nível de dificuldade era aumentado de acordo com o desempenho alcançado.

O objetivo de Santos (1998) consistiu em analisar aspectos estruturais e procedimentais nesse jogo, em crianças que apresentam Síndrome de Down e em crianças "normais", nãoportadores da síndrome. Analisou, em seguida, os níveis de compreensão e explicação dos participantes nesse jogo e dos erros e estratégias utilizadas durante a partida.

De acordo com os resultados obtidos, a referida autora verificou que o jogo escolhido demonstrou ser um instrumento adequado para investigação. Concluiu que a criação de matrizes menores foi uma boa 'estratégia', pois se verificava o desempenho dos participantes nos vários tamanhos de matriz, e o Dominó das Quatro Cores mostrou ser um interessante recurso para ser utilizado com portadores da síndrome na análise de seus processos cognitivos.

Um outro estudo, com base na teoria piagetiana, cujo instrumento utilizado foi a modalidade do Jogo das Quatro Cores denominada Colorindo Figuras Individualmente, foi realizado por Petty, Carracedo e Macedo (1999). O objetivo dos autores consistia em fazer uma análise psicogenética dos procedimentos adotados por crianças com idades entre sete e doze anos. Essa pesquisa desenvolveu-se em duas fases: na primeira fase, o objetivo proposto foi elaborar critérios que caracterizassem os níveis de desempenho de crianças nesse jogo e analisar as condutas observadas, classificandoas de acordo com esses critérios. $\mathrm{Na}$ segunda fase, após uma nova avaliação, utilizando o mesmo jogo, os autores compararam o desempenho das crianças para verificar se houve mudanças. Entre essas duas fases de avaliação, as crianças participaram de oficinas de jogos durante um semestre sem, entretanto, jogar o Jogo das Quatro Cores.

Segundo os autores e, de acordo com os resultados encontrados, foi possível caracterizar três níveis de desempenho:

No nível 1, as regiões são pintadas, quando muito, considerando-se as regras. É possível que as crianças consigam pintar todas as regiões por sorte ou facilidade da proposta, não significando, contudo, que haja intencionalidade em sua conduta. Os protocolos não apresentaram indícios de planejamento da pintura, nem de tentativas de corrigir erros.

No nível 2, já há indícios de planejamento (fazer marcas de cores mais fortes, como se as crianças estivessem analisando uma solução provisória antes de pintar a região por completo). Essa forma de conduta não garante, entretanto, o sucesso na resolução, geralmente devido à dificuldade de a criança desse nível relacionar o todo com as partes. De uma forma geral, ela somente considera a região que está sendo pintada, comparando-a com algumas regiões e perdendo a dimensão do todo. Nesse nível, o erro é percebido, na maioria dos casos, somente depois de ser produzido, o que caracteriza uma forma de conduta por ensaio e erro, na tentativa de solucionar o problema proposto.

Já no nível 3, o desempenho das crianças pode ser caracterizado pela presença de maiores indícios de planejamento (como fazer pequenas marcas com cores em cada região, antes de pintar a figura). Essa forma de resolução permite melhor visualização do resultado, dando maiores chances à criança de corrigir seus erros, caso ocorram. Desse modo, a criança consegue antecipar os erros antes de sua ocorrência, conferindo maior eficácia a seu planejamento e demonstrando haver maior articulação entre as partes (cada região a ser pintada) e o todo (o conjunto de regiões que formam a figura).

Como resultados, os autores constataram que a maioria das crianças $(52,2 \%)$ conseguiu mudar para um nível superior, a minoria $(17,4 \%)$ foi classificada em níveis inferiores, e as restantes $(30,4 \%)$ permaneceram no mesmo nível em relação ao nível constatado inicialmente. 
Com o objetivo de ampliar os dados referentes às pesquisas de Petty, Carracedo e Macedo (1999), Ortega, Fiorot e Silva (2000) realizaram uma pesquisa sobre a relação entre o fazer e o compreender com crianças de idades entre 6 e 14 anos.

Os referidos autores analisaram separadamente as ações das crianças durante o jogo, classificando-as de acordo com os níveis propostos por Petty, Macedo e Carracedo (1999) e, em seguida, analisaram as respostas obtidas em entrevistas sobre como as crianças pensavam antes de realizar suas jogadas, adaptando as perguntas utilizadas por Moreno (1995) em sua pesquisa, podendo, desse modo, analisar as formulações de estratégias mencionadas pelas crianças. Ao relacionar as ações observadas e as justificativas obtidas para tais ações, os autores realizam uma relação entre o fazer e o compreender no Jogo das Quatro Cores.

Com base nos resultados obtidos, Ortega, Fiorot e Silva (2000) elaboraram níveis evolutivos de análise do processo de tomada de consciência ${ }^{3}$, relacionando aspectos observados nas condutas (perspectiva do fazer) e nas formulações de estratégias mencionadas pelas crianças (perspectiva do compreender) no Jogo das Quatro Cores.

Desse modo, partindo do pressuposto de que os jogos de regra são instrumentos válidos para a análise do processo de construção do conhecimento e considerando que, de acordo com Ortega, Fiorot e Silva (2000), o Jogo das Quatro Cores constitui um meio pelo qual a relação entre o fazer e o compreender pode ser analisada, o presente trabalho teve por objetivo investigar, em uma perspectiva psicogenética, a influência do tipo de prática (individual ou em dupla) na solução de problemas contidos em situações de jogos de regras, com base na teoria de Piaget. Assim, procurou-se avaliar crianças de duas idades (de 10 e 12 anos), tanto em relação aos seus desempenhos (se conseguem ou não colorir as figuras propostas e quais são os procedimentos utilizados), quanto aos níveis de compreensão (caracterizados pela relação entre o fazer e o compreender, ou seja, pela relação entre os procedimentos utilizados e as estratégias elaboradas verbalmente) alcançados por elas na solução do problema formulado no Jogo das Quatro Cores.

Essa avaliação foi realizada em dois momentos: antes e depois da prática do referido jogo, com a finalidade de se verificar se ocorrem mudanças no nível de compreensão das crianças e se tais mudanças podem ser atribuídas ao fato de elas terem jogado individualmente ou em dupla.

A escolha desses tipos de prática (individual e em dupla) baseia-se em um estudo realizado anteriormente por Abreu (1993), cujo objetivo consistiu em proceder a análise da construção do sistema de resolução do Jogo da Senha em dezesseis crianças de 5 a 11 anos, tendo como parâmetro os níveis de compreensão propostos por Piaget (1983/1986) para esse jogo.

Este trabalho foi desenvolvido em três sessões: na primeira, as crianças jogaram individualmente; na segunda, em dupla; e na terceira, individualmente.

Segundo a autora acima citada, quando as crianças jogavam em dupla, configurava-se um espaço de troca entre elas, podendo elas sugerir, discutir, argumentar, explicando umas às outras as idéias que acreditavam ser a melhor jogada.

Para Abreu (1993), tal situação era privilegiada por dois motivos. Por um lado, exigia da criança um maior cuidado ao formular suas estratégias e justificativas, pois deveria ser bem sucedida na comunicação com o seu parceiro, de modo a persuadi-lo e a concordar com as estratégias sugeridas. Por outro lado, essa situação de interação entre as crianças trazia ao conhecimento do investigador maiores detalhes sobre as trocas por elas constituídas para a resolução do sistema do Jogo da Senha ${ }^{4}$.

Os resultados obtidos permitiram à autora verificar que a maioria das crianças evoluiu na maneira de jogar, seja pela passagem de um nível para outro, seja até mesmo por saltos significativos na compreensão do sistema do jogo interno aos estágios propostos por Piaget (1983/1986). Além disso, a autora observou que as evoluções mais marcantes ocorreram durante as sessões em que os sujeitos jogavam em duplas. Apesar de esse fato indicar a riqueza e a importância da interação entre as crianças, “ ( . .. ) não se pode afirmar a existência da relação direta entre a sessão de jogo em dupla e o movimento do avanço conceitual, uma vez que não sabemos o que poderia ter acontecido se esta segunda sessão fosse individual" (p. 52).

Partindo dessa constatação, o presente trabalho tem por objetivo ampliar o estudo realizado por Abreu (1993), investigando, de uma maneira sistemática, a influência do tipo de prática (individual ou em dupla) no nível de compreensão de crianças em uma situação-problema contida em um jogo de regras.

A partir desse objetivo mais geral, formularam-se os seguintes objetivos específicos:

verificar se existe diferença significativa entre a relação das idades investigadas e: (a) o desempenho das crianças no jogo, e (b) os níveis de compreensão alcançados por elas na Avaliação Inicial;

constatar se existe diferença significativa entre a relação das idades pesquisadas: (a) e o desempenho das crianças no jogo, e (b) e os níveis de compreensão alcançados por elas na Avaliação Final;

verificar se existe diferença significativa na relação entre os níveis de compreensão alcançados pelas crianças nas duas avaliações, levando-se em consideração o fato de terem praticado o jogo individualmente ou em dupla.

Foi justamente esse último objetivo que permitiu verificar se, de fato, o tipo de prática foi o fator de mudança no nível de compreensão das crianças em relação ao sistema contido no Jogo das Quatro Cores.

\section{Método}

\section{Participantes}

Participaram da presente pesquisa 40 crianças, sendo 20 de 10 anos e 20 de 12 anos, provenientes de duas escolas públicas da Grande Vitória, ES. A escolha dessas idades justifica-se pelo fato de serem de uma faixa etária a partir da qual 
a tomada de consciência se torna possível, indicando que já ocorre maior compreensão do problema proposto em situações contidas em alguns jogos de regras (Moreno, 1995; Ortega, Fiorot \& Silva, 2000, 2001; Piaget, 1974/1978a, 1974/1978b).

Os participantes foram selecionados mediante sorteio, sendo que nenhum deles apresentava dificuldades de aprendizagem escolar, nem conhecia o jogo de regras utilizado como instrumento de investigação no presente trabalho. A pesquisa foi realizada no espaço físico da escola freqüentada pelas crianças.

\section{Instrumento e Procedimento}

Foi utilizada como instrumento de investigação a modalidade do Jogo das Quatro Cores intitulada Colorindo Figuras Individualmente. Foram propostas cinco situações ${ }^{5}$ contidas na referida modalidade do jogo, conforme ilustrações apresentadas na Figura 1.

O problema formulado nessas situações consistia em colorir as referidas figuras, subdivididas em regiões, utilizando-se, no máximo, quatro cores, de maneira que regiões vizinhas não possuíssem a mesma cor.

A presente pesquisa foi realizada em três etapas.

Na primeira etapa, todos os participantes foram avaliados (Avaliação Inicial) de acordo com seus desempenhos na resolução do problema contido em situações do Jogo das Quatro Cores, com o propósito de analisar o nível de compreensão alcançado por eles nessa tarefa.

Desse modo, o problema proposto consistia em colorir as Figuras A, B e C, apresentadas em ordem crescente do número de regiões que as compunham, de modo que a Figura A possuía nove, a Figura B, vinte e duas e a Figura C, vinte e quatro regiões. Foram permitidas, no máximo, três tentativas para solucionar cada situação do problema. Depois que a criança conseguia pintar com sucesso a Figura A, era-lhe apresentada a Figura B, e assim sucessivamente.

Em seguida, com base no método clínico proposto por Piaget, foram formuladas as seguintes questões:

1 - Você pensou alguma coisa antes de pintar as figuras? $\mathrm{O}$ quê?

2 - Você usou alguma estratégia para solucionar o problema? Qual?

3 - Se você tivesse que ensinar outra criança a solucionar o problema, o que você lhe diria?

Todas as tentativas realizadas pelos participantes para solucionar o problema foram registradas em um protocolo e as respostas dadas para cada questão foram gravadas em fitas K-7 e, posteriormente, transcritas em um outro protocolo.

Após a coleta dos dados, foi realizada uma análise microgenética da conduta dos participantes, pois tal modelo de pesquisa permite a observação detalhada do desenrolar de uma partida, jogada após jogada, explicitando as descobertas dos jogadores na busca de uma solução para o problema contido nas situações propostas (Ribeiro, 2001).

De acordo com Inhelder e Caprona (1996), a noção de microgênese implica uma análise pormenorizada das condutas cognitivas em toda sua complexidade natural; um estudo microgenético:

(...) evidencia as características do processo interativo entre o sujeito e o objeto, que havia sido analisado, de modo muito geral por Piaget. Ele permite desvelar a coordenação e a integração eventuais das soluções e dos sucessivos modelos parciais do sujeito (p. 12).

Desse modo, efetuou-se a análise com o propósito de verificar se as crianças: (a) utilizavam algum procedimento para pintar as figuras e (b) justificavam suas ações de acordo

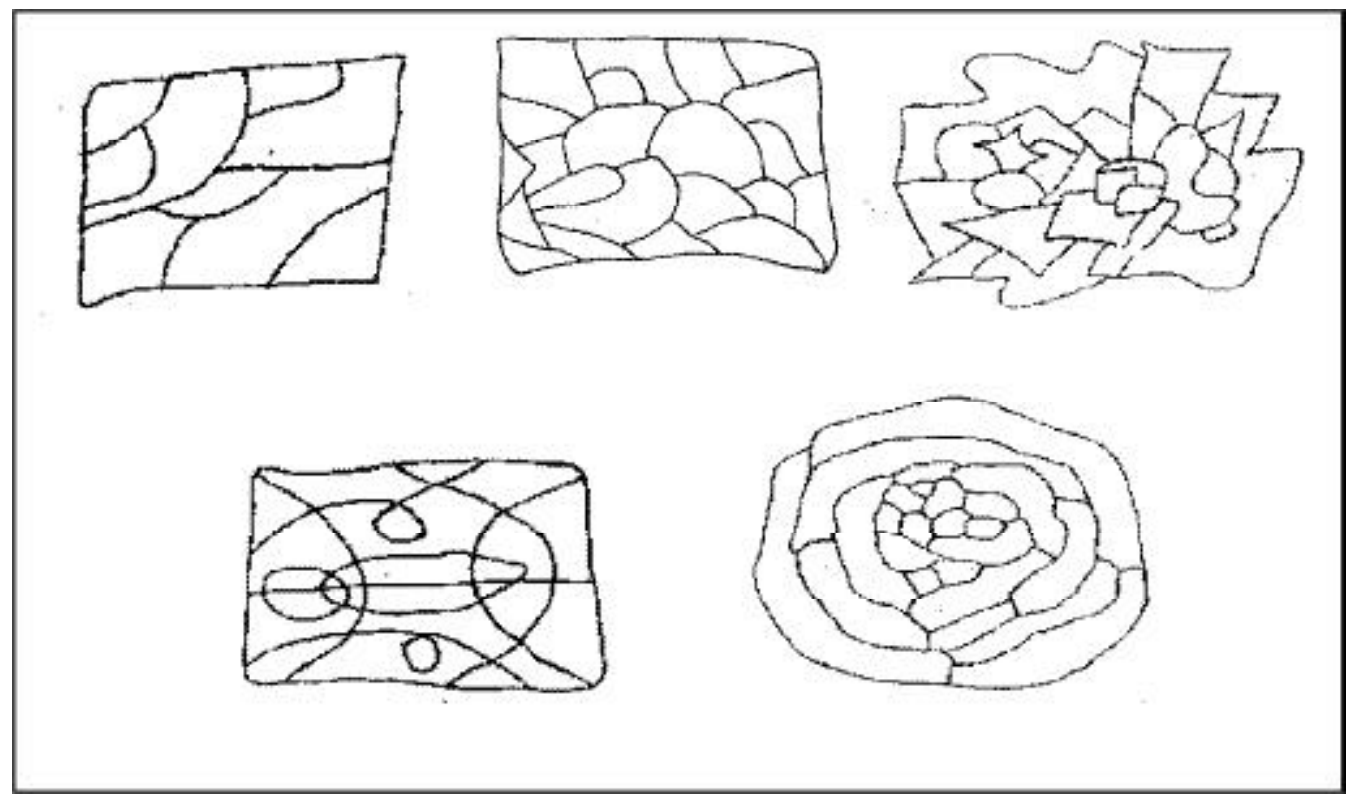

Figura 1

Ilustração das situações contidas no Jogo das Quatro Cores propostas aos sujeitos. 
com as estratégias apontadas por Macedo, Petty e Passos (1997), como necessárias para a solução do problema; ou seja, se elas:

1. pintavam as figuras "economizando cores" (pintavam o máximo de regiões com o mínimo de cores);

2. levavam em consideração a vizinhança (antes de pintar uma região, observavam as adjacências e verificavam o que elas tinham em comum).

Desse modo, com base na utilização desses procedimentos e estratégias, os participantes foram classificados de acordo com os níveis evolutivos propostos por Ortega, Fiorot e Silva (2000) para a análise do processo de tomada de consciência:

Nível Ia: A criança tem dificuldades em entender as regras apresentadas, pinta a figura sem planejamento, muitas vezes não percebe o erro cometido; portanto, não são observadas tentativas de correções. Quanto à compreensão do problema, a criança desse nível não consegue justificar suas ações.

Nível Ib: A criança pode, eventualmente, apresentar indícios de planejamento (como marcas de cores mais fortes). No entanto, esse tipo de planejamento adotado pela criança não lhe garante o sucesso, pois ainda tem dificuldade em articular as partes com o todo, levando em consideração apenas a última região pintada, perdendo a dimensão do todo ao ignorar as regiões adjacentes. O erro, às vezes, é percebido, porém somente após cometido, não permitindo nenhuma tentativa de correção. A conduta da criança desse nível é mais elaborada que sua capacidade de verbalização; assim, há uma preponderância do fazer em relação ao compreender, pois, como no nível anterior, a criança ainda não consegue formular nenhuma estratégia utilizada, não apresentando nenhuma justificativa para suas ações.

Nível Iia: A criança apresenta indícios de planejamento, já consegue articular mais as partes com o todo; porém, ainda não conseguiu descobrir nenhuma das duas estratégias; o erro, como no nível Ib, continua sendo percebido depois de ter sido cometido; todavia há um avanço quanto à formulação de estratégias, sendo que a criança já apresenta indícios de justificativa das ações realizadas.

Nível IIb: A conduta da criança que se encontra nesse nível difere do anterior por ter sua ação caracterizada pela presença de planejamento, como fazer pequenas marcas com cores em cada região, antes de pintar a figura, o que permite melhor visualização do resultado, possibilitando à criança antecipar e pré-corrigir seus erros. Por ser capaz de articular melhor as partes com o todo, a criança desse nível tem um planejamento mais eficaz, contudo não consegue explicar como venceu o jogo. Desse modo, a criança desse nível é capaz de vencer o jogo, porém ainda não desenvolveu sua capacidade de justificar as ações realizadas.

Nível IIc: Como no nível anterior, a criança planeja suas ações, porém pode-se notar um avanço em relação ao nível anterior na medida em que já consegue esboçar alguma justificativa de suas ações. A justificativa mais observada referese à economia de cores.
Nível III - Há um planejamento mais eficaz em relação ao nível anterior, já que a criança consegue articular, de modo mais sistemático, as partes com o todo. Nesse nível, a criança formula as estratégias utilizadas (geralmente a "economia de cores" - utilizando ao máximo apenas três cores, guardando uma para quando não houver outra alternativa), demonstrando haver um planejamento da ação, e as justificativas apresentadas revelam uma total compreensão do problema apresentado.

$\mathrm{Na}$ segunda etapa, foram propostas a todos os participantes novas situações, com o objetivo de proporcionar uma ampliação da prática do Jogo das Quatro cores. O problema consistia em colorir as Figuras D e E, de acordo com os mesmos procedimentos utilizados na primeira etapa.

Tendo em vista que o objetivo principal deste trabalho consistiu em investigar a influência do tipo de prática no nível de compreensão do sistema contido no Jogo das Quatro Cores, as crianças foram divididas, mediante sorteio, em quatro grupos (10 em cada). Enquanto que os Grupos 1 e 3 (10 e 12 anos, respectivamente) tentaram colorir individualmente essas figuras, os Grupos 2 e 4 (10 e 12 anos, respectivamente) tentaram pintá-las em dupla.

$\mathrm{Na}$ terceira etapa da pesquisa, todos os participantes foram reavaliados (Avaliação Final) de acordo com os mesmos instrumentos e procedimentos utilizados na primeira etapa. Desse modo, pudemos estabelecer relações e comparações entre as avaliações inicial e final de cada criança individualmente, verificar a ocorrência de mudanças ou não nos níveis de compreensão do jogo entre essas avaliações, e comparar os resultados dos dados coletados das crianças, de ambas as idades, que jogaram em dupla com os resultados das crianças que jogaram individualmente, podendo, assim, relacionar a possível influência do tipo de prática, com o progresso no nível de compreensão das crianças no Jogo das Quatro Cores.

\section{Resultados e Discussão}

Os resultados obtidos na primeira etapa da pesquisa permitiram verificar, conforme indica a Figura 2, que a maioria dos participantes de ambas as idades conseguiu colorir com êxito a Figura A, na Avaliação Inicial. Entretanto o mesmo não pôde ser verificado em relação às Figuras B e C. Assim, constatou-se que: (a) a maioria das crianças de 10 e 12 anos conseguiu colorir a Figura A (95\%); (b) $15 \%$ das crianças de 10 anos e $55 \%$ das crianças de 12 anos obtiveram sucesso ao pintar a Figura B e (c) apenas 5\% das crianças de 10 anos e $25 \%$ das crianças de 12 anos pintaram corretamente a Figura C.

Comparando-se o desempenho dos participantes de acordo com a idade, notamos um melhor desempenho, por parte das crianças mais velhas, no que se refere às figuras $\mathrm{B}$ e C. Contudo, de acordo com o Teste do Qui-Quadrado, verificou-se que houve diferença significante $(p<0,01)$ apenas no que se refere à idade e à resolução do problema formulado na Figura B.

$\mathrm{O}$ fato de uma maioria dos participantes de ambas as idades ter conseguido pintar com sucesso a Figura A poderia 


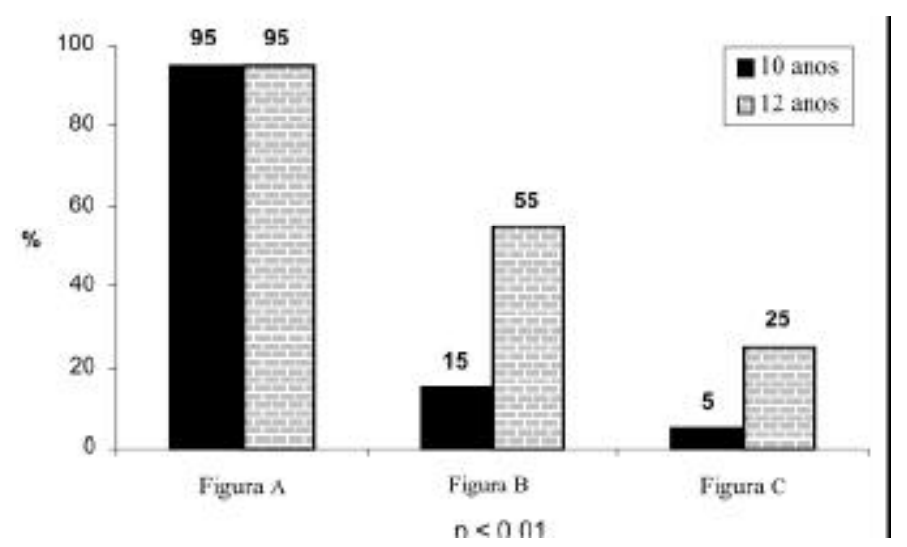

Figura 2

Distribuição percentual do desempenho dos sujeitos nas três situações propostas na Avaliação Inicial.

ser atribuído à facilidade da proposta ou até mesmo à sorte, pois, em alguns casos, a análise de seu desempenho demonstrou não haver indício algum de planejamento quando coloriam essa figura. Em diversas situações, verificou-se que muitas dessas crianças apresentaram certa dificuldade em repetir as cores, pintando as quatro primeiras regiões com as quatro cores, hesitando na hora de colorir a quinta região.

Por outro lado, o percentual reduzido de crianças de 10 anos que solucionaram a Figura B poderia refletir seu grau de complexidade quando comparada à Figura A. Muitas crianças resolviam essa tarefa por tentativa ensaio e erro, não significando, necessariamente, que tenham utilizado algum tipo de estratégia na resolução do problema proposto. Entretanto, por esse tipo de resolução (ensaio e erro) não garantir a vitória em um jogo de regras, pode-se conquistá-la eventualmente, após algumas tentativas fracassadas.

Já as crianças de 12 anos, de um modo geral, tiveram um melhor desempenho ao pintar a Figura B. Esses resultados apontam para maior facilidade das crianças mais velhas em aperfeiçoar suas estratégias diante de um fracasso inicial, e, caso seja necessário, modificá-las para conseguir vencer o jogo. Além disso, foi constatado que o erro para essas crianças se torna mais facilmente um observável, pois conseguem percebê-lo logo após tê-lo cometido. Assim, quando o erro se torna um observável, as crianças têm a chance de analisar a situação em que foi produzido, podendo, posteriormente, elaborar estratégias que evitem as situações em que foram cometidos. Portanto, analisando essas situações e aperfeiçoando as estratégias elaboradas, as crianças mais velhas têm mais chances de serem bem sucedidas na resolução do problema.

No que se refere aos níveis de compreensão (caracterizados pela relação entre os procedimentos adotados e as estratégias formuladas verbalmente) alcançados pelos participantes na resolução do problema formulado nas situações contidas no Jogo das Quatro Cores na Avaliação Inicial, verificouse, como pode ser observado na Figura 3, que: (a) a maioria das crianças de 10 anos encontra-se no nível Ia; (b) a mesma quantidade de crianças de 10 e 12 anos encontra-se no nível Ib; (c) um número maior de crianças de 12 anos encontra-se nos níveis IIa, IIb e IIc; (d) apenas uma criança de 10 anos encontra-se no nível III.

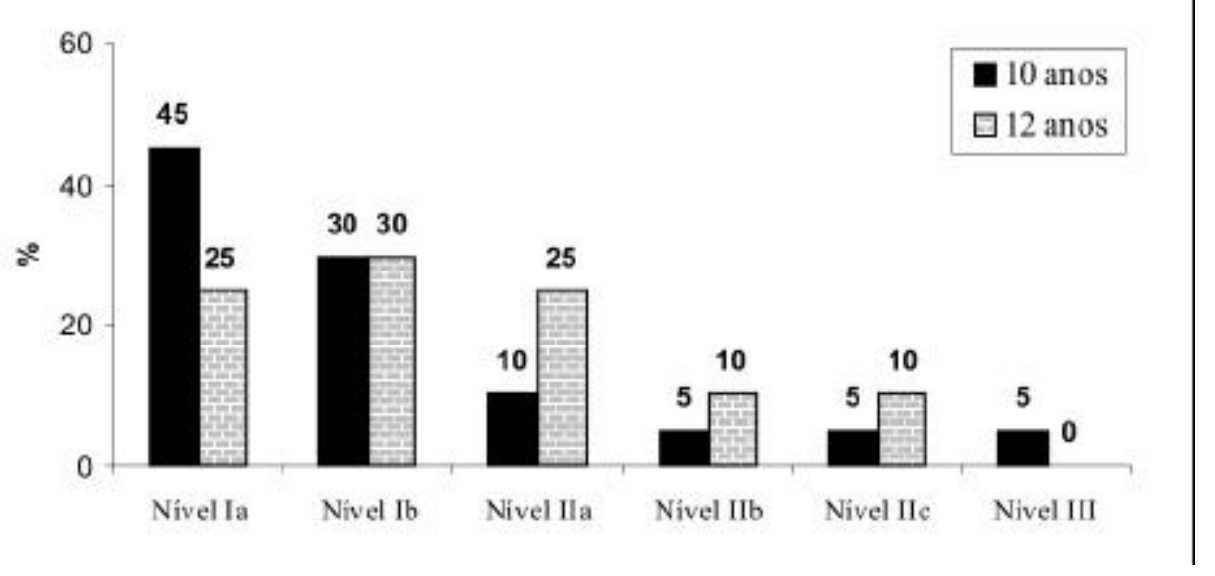

Figura 3

Distribuição percentual dos níveis de compreensão alcançados pelos sujeitos na Avaliação Inicial. 


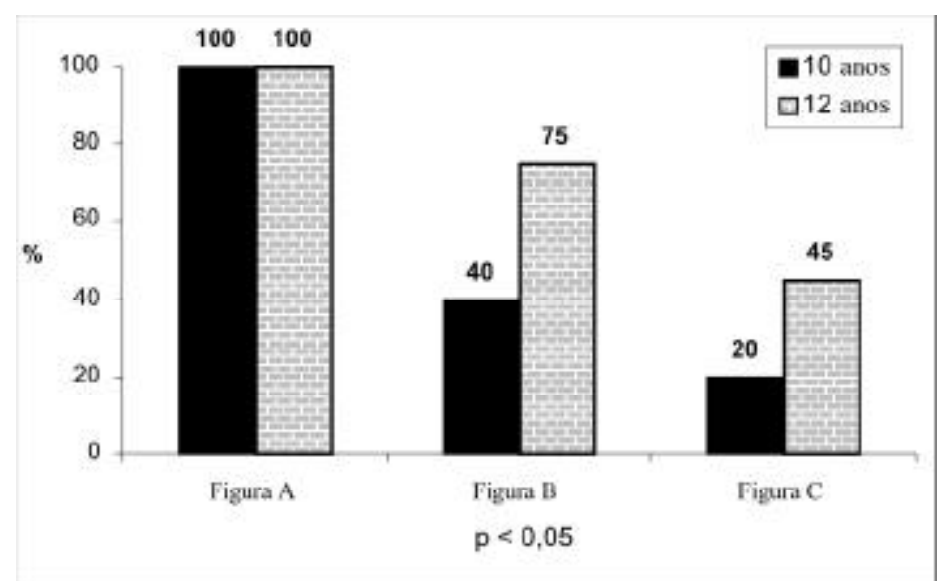

Figura 4

Distribuição percentual do desempenho dos sujeitos nas três situações propostas na Avaliação Final.

De acordo com o Teste Mann-Whitney, constatou-se que não houve diferença significante ao se relacionar a idade das crianças e os níveis de compreensão alcançados por elas.

A constatação de que a maioria dos participantes alcançou o nível I pode ser explicado a partir do tema teórico referente ao fazer e compreender. Para Piaget (1974/1978a),

(...) fazer (réussir) é compreender em ação uma situação dada em grau suficiente para atingir os fins propostos, e compreender é conseguir dominar em pensamento as mesmas situações até poder resolver os problemas por elas levantados, em relação do como e ao porquê das ligações constatadas e, por outro lado, utilizadas na ação (p. 176).

Assim, em relação ao fazer, em muitos casos as figuras eram coloridas aleatoriamente, sem demonstrar nenhum tipo de planejamento. Em conseqüência disso, podemos verificar que a maioria desses participantes conseguiu colorir apenas a Figura A. Já no que se refere ao compreender, essas crianças não conseguiram esboçar justificativa alguma para suas jogadas, muitas vezes apenas repetindo as regras do jogo.

De um modo geral, o desempenho das crianças mais velhas foi sensivelmente melhor, indicando de certa forma que, em relação à perspectiva do fazer, elas apresentaram algum indício de planejamento e seus resultados diferiram dos encontrados a partir das crianças mais novas. Entretanto, assim como verificado nos resultados a partir dos resultados obtidos das crianças mais jovens, a maioria das crianças de 12 anos também não conseguiu elaborar indícios das estratégias utilizadas.

Além disso, verificamos que $20 \%$ das crianças de 10 anos e quase a metade das crianças de 12 anos (45\%) foram classificados no nível II, cujo desempenho pode ser caracterizado pela utilização de algum tipo de estratégia, que resultou no sucesso em colorir a Figura A e, eventualmente, também em colorir a Figura B.

Portanto, no que se refere ao fazer, notamos que todas essas crianças apresentaram vários indícios de planejamento como, por exemplo, fazer marquinhas com as cores em cada região antes de pintá-las. Quanto à formulação de estratégias, verificamos que essas crianças foram bem sucedidas em formular indícios de justificativas de suas jogadas, porém ainda não estavam convictas do que falavam, demonstrando ter uma compreensão apenas parcial do problema proposto.

Entretanto, o compreender nas crianças de 12 anos não diferiu, de um modo geral, da compreensão alcançada pelas crianças mais novas. Suas formulações eram semelhantes, o que demonstrou haver uma predominância do fazer em relação ao compreender no jogo, levando-se em consideração as idades observadas. Tal constatação reafirma o que assinalam Piaget (1974/1978a, 1974/1978b), Moreno (1995) e Ortega, Fiorot e Silva (2000 e 2001) em seus estudos sobre o processo da tomada de consciência, caracterizados pela relação entre o fazer e o compreender.

Após o período dedicado à prática do jogo, realizada na segunda etapa da pesquisa (na qual os participantes dos grupos 1 e 3 tentaram solucionar individualmente o problema contido nas Figuras D e E e os dos grupos 2 e 4 tentaram solucioná-lo em dupla), verificou-se na Avaliação Final que todos os participantes conseguiram resolver a Figura A. Entretanto, a exemplo do que foi verificado na Avaliação Inicial, o desempenho dos participantes também foi diferenciado em relação às outras duas figuras. Dessa forma, constatou-se, conforme assinala a Figura 4, que: (a) todas as crianças (100\%) de 10 e 12 anos pintaram com êxito a Figura A; (b) $40 \%$ das crianças de 10 anos e $75 \%$ das de 12 anos conseguiram pintar corretamente a Figura B; e (c)20\% das crianças de 10 anos e $45 \%$ das de 12 anos foram bem sucedidas ao pintar a Figura C.

Com base nesses resultados, verificou-se um melhor desempenho por parte das crianças mais velhas, tanto em relação à Figura B quanto à Figura C. No entanto, de acordo com o Teste do Qui-Quadrado, constatou-se que houve diferença significante $(\mathrm{p}<0,05)$ apenas em relação à idade e à resolução do problema formulado na Figura B.

Em relação aos níveis de compreensão alcançados pelos participantes na resolução do problema contido nas três situações do Jogo das Quatro Cores na Avaliação Final, verifi- 


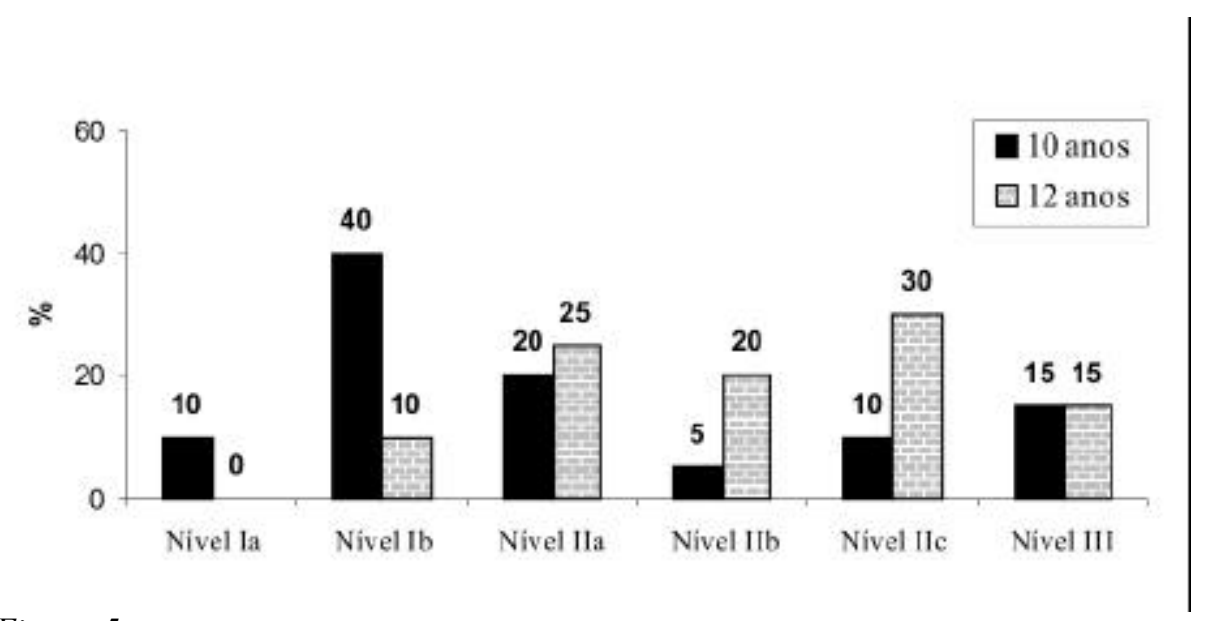

Figura 5

Distribuição percentual dos níveis de compreensão alcançados pelos sujeitos na Avaliação Final

cou-se, como pode ser observado na Figura 5, que: (a) a maioria das crianças de 10 anos encontra-se no nível Ib; (b) um número maior de crianças de 12 anos encontra-se no nível IIa, IIb e IIc; (c) a mesma quantidade de crianças de cada idade encontra-se no nível III.

De acordo com o Teste de Mann-Whitney, constatou-se que houve diferença significante $(\mathrm{p}<0,05)$ quando se relaciona a idade das crianças e os níveis de compreensão alcançados por elas.

Comparando-se esses resultados com os obtidos na primeira etapa, verificou-se que houve melhora em relação ao nível de compreensão da maioria dos participantes. No entanto, de acordo com o Teste de Análise de Variância ( $\mathrm{p}=$ $0,435)$, constatou-se que não houve diferenças significativas quanto ao fato de as crianças terem praticado o jogo individualmente ou em dupla. Assim, verificou-se que a maioria das crianças $(67,5 \%)$ avançou nos níveis de compreensão do jogo, sendo que $35 \%$ o praticaram individualmente e $32,5 \%$ em dupla.

Portanto, apesar de se constatar melhora no nível de compreensão dos participantes após a prática do Jogo das Quatro Cores, essa melhora não foi significativa, não podendo, conseqüentemente, ser atribuída aos tipos de prática investigados. Desse modo, os dados obtidos parecem indicar que o principal fator de contribuição para o avanço no nível de compreensão dos participantes poderia ser atribuído à ampliação da prática do referido jogo, por meio de novas situações-problema.

A ampliação dessa prática pode levar os participantes a à re-elaborar suas estratégias e facilitar o processo que os leva à compreensão total do jogo. Pode-se fazer tal afirmação porque essa foi uma variável existente nos dois grupos formados (tanto as crianças que jogaram individualmente quanto as que jogaram em dupla tiveram a chance de praticar o jogo), portanto, comum a todos os participantes.

Vários trabalhos realizados (Abreu, 1993; Barone \& Macedo, 1997; Petty, Carracedo \& Macedo, 1999) indicam que a prática do jogo, acompanhada de um processo de intervenção, pode ser um fator que contribui para o aperfeiçoamento de procedimentos e estratégias utilizadas.

Enfocando a análise da relação entre o fazer e o compreender, podemos afirmar que, a partir do momento em que há êxito em solucionar um problema proposto, é provável que também sejamos bem sucedidos ao formular as estratégias que utilizamos, fato que está intimamente ligado à importância da prática do jogo.

\section{Considerações Finais}

Acreditamos que o presente trabalho tenha fornecido algumas contribuições ao estudo da prática de jogos de regras e sua relação com o desenvolvimento cognitivo infantil. Contudo estamos cientes das limitações do presente trabalho e, diante disso, destacamos alguns pontos relevantes e propomos algumas sugestões no que se refere ao método adotado.

Inicialmente, vale salientar, assim como foi verificado em pesquisas anteriores (Ortega, Fiorot \& Silva, 2000, 2001; Petty, Carracedo \& Macedo, 1999), que a modalidade do Jogo das Quatro Cores, denominada Colorindo Figuras Individualmente, constitui um instrumento válido na avaliação dos processos cognitivos.

Por meio do Jogo das Quatro Cores, assim como assinalam Macedo, Petty e Passos (1997), podemos evidenciar importantes aspectos da aprendizagem escolar. Ao jogá-lo, a criança exercita sua coordenação motora (pois o jogar, nesse caso, implica também uma ação puramente motora que consiste na pintura de cada região, dentro de limites preestabelecidos). Além disso, estimula sua concentração (o jogador deve estar atento para não realizar jogadas que o impeça impeçam de seguir adiante), além de propiciar aos participantes situações nas quais o processo pela busca de uma solução requer, necessariamente, o planejamento.

No ato de planejar está implícito, além da ação motora propriamente dita, um raciocínio lógico baseado na operação 
de negação e afirmação, que pode ser verificada a partir do ato da criança de negar algumas cores em função do que já foi feito, levando em consideração as regras do jogo.

Além disso, jogar o Quatro Cores, principalmente a modalidade utilizada na presente pesquisa, também permite à criança analisar sua própria ação. Ao terminar de colorir a situação proposta, a criança pode avaliar suas jogadas e, eventualmente, perceber seus erros, passando a antecipálos; isso somente é possível porque, quando há erro ou uma região em branco cercada de outras com as quatro cores, a criança percebe imediatamente o erro cometido.

Em relação aos níveis de compreensão do jogo, propostos por Ortega, Fiorot e Silva (2000), confirmamos a adequação de sua classificação para a análise da relação entre o fazer e o compreender. Entretanto, por ser uma proposta recémelaborada, acreditamos na necessidade de realização de outras pesquisas a fim de contribuir para o esclarecimento de algumas lacunas, assim como para validar tal classificação.

A partir dessas considerações, propomos que se investigue a questão da prática do Jogo das Quatro Cores, em trabalhos futuros, com uma faixa etária mais abrangente do que a pesquisada, com o propósito de possibilitar a análise dos processos necessários à construção de procedimentos e estratégias necessárias à compreensão do sistema contido nesse jogo ou em outros jogos de regras.

Sugerimos ainda que, em um estudo posterior, se amplie o número de situações-problema formuladas no contexto do Jogo das Quatro Cores e que também seja aumentado o número de sessões destinadas à prática do referido jogo. Seria interessante, em estudos longitudinais como este, que se introduza, nas sessões de prática, um trabalho de intervenção, com a finalidade de se investigar o processo da tomada de consciência.

Questões como essas surgem após uma análise mais detalhada dos dados coletados e são expostas com o intuito de que possam contribuir para uma aplicação do conhecimento produzido no processo de elaboração deste trabalho, seja nos consultórios, seja nas salas de aula.

Certamente, é um trabalho recompensador, pois nos auxilia, em uma perspectiva psicopedagógica, a construir modelos de didática mais eficazes, que sejam mais produtivos no que se refere ao processo de construção do conhecimento. Estudos como este produzem questionamentos e abrem possibilidades para uma prática psicopedagógica fundamentada na construção do conhecimento a partir de diferentes tipos de prática, implicando trocas sociais, que permeiam nossa vida e que têm muito a contribuir para o desenvolvimento cognitivo das crianças.

\section{Referências}

Abreu, A. R. (1993). O jogo de regra no contexto escolar: uma análise na perspectiva construtivista. Dissertação de mestrado não-publicada, Universidade de São Paulo, São Paulo.

Barone, K. C., \& Macedo, L. (1997). O jogo ta-te-ti e suas dimensões dialética e simbólica. Trabalho não-publicado, Universidade de São Paulo, São Paulo.

Inhelder, B., \& Caprona, D. (1996). Rumo ao construtivismo psicológico: estruturas? procedimentos? os dois "indissociáveis". In B. Inhelder et al., $O$ desenrolar das descobertas da criança: um estudo sobre as microgêneses cognitivas. (pp. 7-37). Porto Alegre: Artes Médicas.

Macedo, L. (1992). Novas contribuições da psicologia aos processos de ensino e aprendizagem. In E. S. Alencar (Org.), Para uma psicopedagogia construtivista. (pp.119-140). São Paulo: Cortez.

Macedo, L., Petty A. L. S., \& Passos, N. C. (1997). Quatro Cores, Senha e Dominó: oficinas de jogos em uma perspectiva construtivista e psicopedagógica. São Paulo: Casa do Psicólogo.

Moreno, A. (1995). Autorregulación y solución de problemas: un punto de vista psicogenético. Infancia y Aprendizaje, 72, 51-70.

Ortega, A. C., Fiorot, M. A., \& Silva, L. C. M. (2000). O fazer e o compreender no jogo das Quatro Cores: uma análise psicogenética. Trabalho nãopublicado, Universidade Federal do Espírito Santo, Vitória.

Ortega, A. C., Fiorot, M. A., \& Silva, L. C. M. (2001). Aspectos psicogenéticos da tomada de consciência em um contexto de jogos. Trabalho não-publicado, Universidade Federal do Espírito Santo, Vitória.

Petty, A. L. S. (1995). Ensaio sobre o valor pedagógico dos jogos de regras: uma perspectiva construtivista. Dissertação de mestrado não-publicada, Universidade de São Paulo, São Paulo.

Petty, A. L., Carracedo, V., \& Macedo, L. (1999). O Jogo em uma perspectiva piagetiana: uma análise psicogenética a partir do jogo 4 cores. Trabalho não-publicado, Universidade de São Paulo. São Paulo.

Piaget, J. (1978a). Fazer e compreender. São Paulo: Melhoramentos: Editora da USP (Obra original publicada em 1974).

Piaget, J. (1978b). A tomada de consciência. São Paulo: Melhoramentos; Editora da USP (Obra original publicada em 1974).

Piaget, J. (1986). O possivel e o necessário: evolução dos necessários na criança (vol. 2). Porto Alegre: Artes Médicas (Obra original publicada em 1983).

Ribeiro, M. P. O. (2001). Funcionamento cognitivo de crianças com queixas de aprendizagem: jogando e aprendendo a jogar. Tese de doutorado nãopublicada, Universidade de São Paulo, São Paulo.

Santos, C. C. (1998). O raciocínio de crianças no Jogo das Quatro Cores em um contexto psicogenético. Revista Psicopedagogia, 45, 13-17.

\section{Nota}

Artigo referente à Dissertação de Mestrado da primeira autora, sob a orientação do segundo.

Histórico e descrição das modalidades do Jogo das Quatro Cores, baseado em Macedo, Petty e Passos (1997).

Esses níveis serão descritos detalhadamente na parte referente ao Método.

4 O tema da interação social foi abordado de uma maneira sistemática na Dissertação de Mestrado, da qual o presente trabalho faz parte, e será objeto de um outro artigo a ser elaborado.

5 Figuras retiradas da obra de Macedo, Petty e Passos (1997). 
Lorena Carla Macedo da Silva, mestre em Psicologia pela Universidade Federal do Espírito Santo, é professora da Faculdade Ítalo-Brasileira, Cariacica, ES.

Endereço para correspondência: Rua Milthor de Oliveira Fernandes, 65/506, Jardim Camburi, 29090-760, Vitória, ES. E-mail: lorenamacedo@ hotmail.com.

Antonio Carlos Ortega, doutor em Psicologia pela Fundação Getúlio Vargas, RJ, é professor e pesquisador do Programa de Pós-Graduação em Psicologia da Universidade Federal do Espírito Santo, ES. 